\title{
CARACTERÍSTICAS MICROBIOLÓGICAS DO LEITE TIPO A "IN NATURA" E PASTEURIZADO EM DIFERENTES PONTOS DO FLUXOGRAMA DE BENEFICIAMENTO
}

\author{
ANTONIONADER FILHO' \\ LUIZ AUGUSTO DO AMARAL'1 \\ DANIELA BEATRIZLÉOZ SCHOCKEN² \\ ALESSANDRA RICARDO DIMENSTEIN³
}

NADER FILHO, A., AMARAL, L.A., SCHOCKEN, D.B.L., DIMENSTEIN, A.R. Características microbiológicas do leite tipo a "In natura" e pasteurizado em diferentes pontos do fluxograma de beneficamento. Semina: Ci. Agr., Londrina, v.19, n.1, p.21-25, mar. 1998.

RESUMO: Foram submetidas às contagens de microrganismos mesótilos e às pesquisas de coliformes totais, coliformes fecais e de Staphylococcus aureus, 120 amostras de leite crue pasteurizado, colthidas em diferentes pontos do fluxograma de beneficiamento de uma mini-usina de beneficiamento de leite tipo A. Apesar de todas as amostras analisadas mostrarem-se negativas ante a pesquisa de S.aureus, os resultados obtidos evidenciaram que $18(75,0 \%)$ amostras de leite colhidas no tanque de leite cru, assim como $6(25,0 \%), 8(33,3 \%)$ e 11 (45,8\%) amostras de leite pasteurizado colhidas no tanque de estocagem de leite pasteurizado, tanque de equilibrio e saída da máquina de envase, respectivamente, apresentaram-se tora dos padröes microbiológicos legais.

PALAVRAS-CHAVE: Leite, leite tipo A, mini-usina de beneficiamento de leite.

\section{INTRODUÇĀO}

Apesar do crescente interesse pela produçăo de leite pasteurizado "tipo A" verificado nos últimos anos em nosso meio, pouquíssimas são as informaçōes disponiveis sobre a qualidade microbiológica do produto distribuído ao consumo. Silveira et al. (1988) e Nader Filho et al. (1990), investigando as caracteristicas microbiológicas do leite tipo A comercializado nas cidades de São Paulo/SP e de Ribeirão Preto/SP, verificaram que $64,7 \%$ e $40,9 \%$ das amostras analisadas, respectivamente, apresentaram-se fora dos padrões estabelecidos pelo Ministério da Saúde.

A ocorrência de falhas no processo de beneficiamento (Borges et al., 1978; Nascimento, 1982; Nader Filho et al., 1989a,b), aliadas às elevadas temperaturas de conservaçāo do produto no comércio varejista (Borges et al. 1978; Nascimento, 1982; Oliveira \& Borges, 1983), sāo fatores que podem contribuir significativamente para a comercializaçăo dos diferentes tipos de leite pasteurizado com características microbiológicas fora dos padrōes legais (Rossi Júnior et al., 1982; Nader Filho et al., 1987).

Tendo em vista o exposto e considerando a ausencia de informações sobre a qualidade do leite pasteurizado tipo A a nivel de mini-usina de beneficiamento, idealizouse o presente trabalho com a finalidade de conhecer as características microbiológicas do produto "in natura" e pasteurizado em diferentes pontos do fluxograma, além de comparar os resultados obtidos com os padrões estabelecidos pelo Ministério da Agricultura e de detectar os prováveis pontos críticos de contaminaçāo deste tipo de leite.

\section{MATERIAL E MÉTODOS}

Durante o período de julho de 1996 a maio de 1997 , foram colhidas 24 amostras de leite cru e 96 de leite pasteurizado, em diferentes pontos do fluxograma de uma mini-usina de beneficiamento de leite tipo A, com fiscalização do Serviço de Inspeção da Secretaria de Agricultura do Estado de Sāo Paulo (SISP).

\section{Obtençăo das amostras de leite}

Amostras de $250 \mathrm{ml}$ de leite foram colhidas no tanque de estocagem de leite cru, saída da seçăo de resfriamento do pasteurizador, tanque de estocagem de leite pasteurizado, tanque de equilíbrio da maquina envase e $1000 \mathrm{ml}$ (embalagem plástica comercial) na saida do envase, de acordo com as normas de assepsia propostas por Veisseyre (1972). As amostras foram transportadas e mantidas sob refrigeração até o momento das análises laboratoriais.

\footnotetext{
- Docente do Departamento de Medicina Veterinária Preventiva, Faculdade de Cièncias e Veterinárias, Universidade Estadual Paulista, Jaboticabal - SP - Brasil, CEP 14870.000.

- Bolsista da FAPESP. Departamento de Medicina Veterinária Preventiva, Faculdade de Ciências Agrárias e Veterinárias, Universidadie Estadual Paulista, Jaboticabal/SP - Brasil, CEP: 14870-000.

${ }^{3}$ Bolsista do $\mathrm{CNPq}$, Departamento de Medicina Veterinária Preventiva, Faculdade de Cièncias Agrãrias e Veterinárias, Universidade Estadual Paulista, Jaboticabal/SP - Brasil, CEP: 14870-000.
} 


\section{Contagens de microrganismos mesófilos}

Para a execuçăo desta prova, após a homogeneização das amostras de leite, preparavam-se diluiçöes de $10^{\prime}$ até $10^{-4}$, empregando-se como diluente solução de peptona a $0,1 \%$. Em seguida, $1,0 \mathrm{ml}$ de cada diluiçäo era colocado em placas de Petri esterilizadas, em duplicatas, vertendo-se, a seguir, cerca de $15 \mathrm{ml}$ de ágar padrăo, previamente fundido e resfriado a $43 / 45^{\circ} \mathrm{C}$.

Após a homogeneização e solidificação do ágar em temperatura ambiente, as placas foram incubadas a $32^{\circ} \mathrm{C}$ por 48 horas, quando efetuavam-se as conta gens das colônias. A média aritmética do número de colônias contadas nas placas contendo entre 30 e 300 colônias, era multiplicada pelo fator de diluiçäo correspondente e - resultado obtido expressava o número de unidades formadoras de colônias por mililitro de leite (APHA, 1976).

\section{Pesquisa de coliformes totais}

Foram inoculados $1,0 \mathrm{ml}, 0,1 \mathrm{ml} \mathrm{e} 0,01 \mathrm{ml} d a$ amostra de leite em tubos de ensaio contendo caldo lactose bile verde brilhante a $2 \%$ e tubos de Durhan invertidos, em triplicatas. Após a incubação a $37^{\circ} \mathrm{C}$ por 24/48 horas, foram consideradas positivas para a pesquisa de coliformes totais, as amostras que apresentavam produçāo de gás. Através da utilização da tabela de Hoskins, quantificava-se a presença de coliformes totais cujo resultado era expresso em NMP por mililitro de leite (APHA, 1976; MINISTÉRIO DA AGRICULTURA, 1981).

\section{Pesquisa de coliformes fecais}

A pesquisa de coliformes fecais foi efetuada a partir de cada um dos tubos de ensaio contendo caldo lactose bile verde brilhante que apresentasse positividade ante a pesquisa de coliformes totais. Assim, transferia-se uma alçada da cultura para tubos de ensaio correspondentes contedo $10 \mathrm{ml}$ de caldo $\mathrm{EC}$ e tubos de Durhan invertidos. Após a incubaçāo em banho maria a $44,5^{\circ} \mathrm{C}$ por 24 horas foram consideradas positivas para coliformes fecais as amostras que apresentavam turvaçāo do meio e produção de gás. Através da utilização da tabela do Número Mais Provável (NMP), quantificava-se a presença de coliformes fecais, cujo resultado era expresso em NMP por mililitro de leite (APHA, 1976; MINISTÉRIO DA AGRICULTURA, 1981).

\section{Pesquisa de Staphylococcus aureus}

Depositava-se na superficie do ágar Baird-Parker em placas, 0,1 ml das amostras de leite a serem analisadas. A seguir, o inoculo era espalhado por toda a superfície do meio, através da utilizaçāo de bastōes de vidro em "L" esterilizado. Após a incubação a $37^{\circ} \mathrm{C}$ por 24/48 horas, foram contadas as colônias negras, briihantes, com zona de precipitaçāo ao redor, circundadas ou nāo por halo claro. O número de colônias contado foi multiplicado por 10, a fim de se obter o número presuntivo de $S$. aureus por mililitro de leite.
Em seguida 3 a 5 colônias eram submetidas a verificaçāo microscópica em esfregaços corados pelo método de Gram. As colónias que revelassem a presença de cocos Gram positivos, agrupados em forma de cachos, foram isoladas e semeadas em tubos de ensaio contendo caldo de infusāo de cérebro e coraçāo (BHI) e incubadas a $37^{\circ} \mathrm{C}$ por 24 horas. Após este período, realizava-se a identificaçäo bioquímica através das provas de coagulase, termonuclease, produçāo de catalase, acetoina e a utilizaçâo em aerobiose e anaerobiose da maltose e trealose, segundo as técnicas descritas por MAC FADIM (1976).

Em funçāo dos resultados obtidos nestas provas, procedia-se a identificaçăo dos Staphylococcus aureus de acordo com Carter \& Cole Junior (1990). Após esta identificaçāo bioquímica, o resultado da contagem presuntiva era confirmado ou corrigido.

\section{RESULTADOS}

A Tabela 1 mostra a distribuiçāo das contagens de microrganismos mesófilos viáveis em amostras de leite tipo A "in natura" e pasteurizado. Observa-se que tanto a média aritmética $(27.065 \mathrm{ufc} / \mathrm{ml})$ como a média geométrica $(17.803 \mathrm{ufc} / \mathrm{ml})$ das contagens de microrganismos mesófilos das amostras de leite "in natura", apresentaram valores acima do limite máximo (10.000 ufc/ml) permitido pelo padrão legal (MINISTERIO DA AGRICULTURA, 1991). Das 24 amostras de leite "in natura" analisadas, $18(75,0 \%)$ apresentaram contagens de microrganismos mesófilos acima do referido padrāo.

Os dados da Tabela 1 revelam contagens de microrganismos mesófilos das amostras de leite pasteurizado com valores crescentes das médias aritmética e geométrica desde a saida do pasteurizador (169 ufc/ml e $95 \mathrm{ufc} / \mathrm{ml}$, respectiva mente) até a saída do envase ( $814 \mathrm{ufc} / \mathrm{ml}$ e $316 \mathrm{ufc} / \mathrm{ml}$, respectivamente).

A Tabela 2 mostra a distribuiçāo das amostras de leite pasteurizado do tipo A fora dos padróes estabelecidos pelo Ministério da Agricultura, segundo as contagens de microrganismos mesófilos, pesquisas de coliformes totais, coliformes fecais e de Staphylococcus aureus. Observa-se que todas as 24 amostras de leite pasteurizado colhidas na saída do pasteurizador apresentaram-se dentro dos referidos padrões legais. Todavia, entre as amostras colhidas no tanque de estocagem, verificou-se a ocorrência de $6(25,0 \%), 6(25,0 \%)$ e de $4(16,7 \%)$ amostras fora dos padróes estabelecidos para as contagens de microrganismos mesófilos e para as pesquisas de coliformes totais e de coliformes fecais, respectivamente.

Os dados da Tabela 2 revelam $6(25,0 \%), 8(33,3 \%)$ e $5(20,8 \%)$ amostras colhidas no tanque de equilibrio e $8(33,3 \%), 11(45,8 \%)$ e $4(16,7 \%)$ amostras obtidas na saida do envase, fora dos padrōes legais estabelecidos para as contagens de microrganismos mesófilos e para as pesquisas de coliformes totais e de coliformes fecais, respectivamente. A pesquisa de 
S. aureus mostrou-se negativa em todas as amostras de leite pasteurizado analisadas.

\section{DISCUSSÃO E CONCLUSŌES}

A Tabela 1 revela a ocorrência de $18(75,0 \%)$ amostras de leite tipo "in natura", cujas contagens de microrganismos mesófilos aeróbios ou facultativos viáveis, situaram-se acima do limite permitido pelo Ministério da Agricultura. Este achado talvez possa ser atribuído às falhas ou descuidos ocorridos na aplicaçāo das medidas higiênicas durante o processo de obtençāo do leite.

As $24(100,0 \%)$ amostras de leite tipo A pasteurizado, colhidas na saída da seçāo de resfriamento do pasteurizador, apresentaram-se com contagens de microrganismos mesófilos dentro dos referidos padrōes legais, sendo este achado justificado pela eficiência do pasteurizador utilizado pela miniusina objeto desta investigaçăo.

A análise dos dados da Tabela 1 evidencia, também, que as contagens de microrganismos mesófilos das amostras de leite pasteurizado, apresentaram valores crescentes desde a saida da seçāo de resfriamento do pasteurizador até a saída da máquina de envase. Observaçōes semelhantes foram realizada por Nader Filho (1987) ao analisar amostras de leite pasteurizado tipo $B$, colhidas em uma usina de beneficiamento do Estado de São Paulo. O referido autor atribuiu este fato à provável ocorrência de falhas do processo de higienizaçāo das tubulaçóes e dos equipamentos que entram em contato direto com o leite pasteurizado

Apesar de ter sido verificada a ocorrencia de valores crescentes das contagens de microrganismos mesófilos entre as amostras de leite pasteurizado colhidas desde a saida da seçáo de resfriamento do pasteurizador até a saída do envase, a análise dos dados inseridos na Tabela 1 revela, ainda, que as maiores variaçōes das médias aritmética e geométrica das referidas contagens foram constatadas entre a saida da seçāo de resfriamento do pasteurizador e o tanque de estocagem. Este achado parece caracterizar a existência de um ponto crítico de contaminaçāo deste produto nesta etapa do fluxograma de beneficiamento da mini-usina objeto desta investigaçāo.
A análise dos dados constantes da Tabela 2 revela a ocorrência de $11(45,8 \%)$ amostras fora dos padrões legais estabelecidos para as contagens de microrganismos mesófilos, coliformes totais e/ou coliformes fecais. Este achado aliado a ausência de amostras fora dos referidos padrōes na saida da seçäo de resfriamento do pasteurizador, sugere a possibilidade da ocorrência de contaminaçāo do produto entre a saída do pasteurizador e a saida da máquina de envase. Observaçōes semelhantes foram realizadas por Nader Filho (1987) ao analisar amostras de leite pasteurizado tipo B, colhidas em uma usina de beneficiamento do Estado de São Paulo. O referido autor atribuiu este fato à provável ocorrência de falhas de higienizaçāo das tubulaçōes e equipamentos que entram em contato direto com o leite pasteurizado.

A Tabela 2 mostra, também, a ocorrência de um número crescente de amostras fora dos padróes legais frente às contagens de microrganismos mesófilos e pesquisas de coliformes totais e fecais, desde o tanque de estocagem até a saída da máquina de envase. Todavia, a análise dos dados inseridos nesta Tabela, revela que entre as $11(45,8 \%)$ amostras de leite pasteurizado tipo A fora dos referidos padrōes, 6 $(25,0 \%)$ destas já haviam sido contaminadas no tanque de estocagem. Depreende-se, portanto, que mais da metade do número total de amostras fora dos referidos padrōes legais, foram contaminadas entre a saída da seção de resfriamento do pasteurizador e o tanque de estocagem. Este achado parece ratificar a afirmaçāo inserida na análise da Tabela 1, no sentido de caracterizar a existência de um ponto crítico de contaminaçāo do produto nesta etapa do fluxograma de beneficiamento da mini-usina objeto desta investigaçāo.

Apesar de ter sido verificada a ausência de isolamento de cepas de $S$. aureus em todas as amostras de leite pasteurizado analisadas, os resultados obtidos no presente trabalho constituemse em motivo de preocupaçāo, uma vez que a ocorrencia de amostras fora dos padrốes legais na própria mini-usina objeto desta investigação, além de evidenciar a existencia de falhas no processo de beneficiamento, revela, também, que antes mesmo da distribuição e comercialização, este produto já apresenta uma qualidade microbiológica inferior à estabelecida para a sua especificaçāo. 
Tabela 1. Contagens de microrganismos mesófilos viáveis em amostras de leite tipo a "in natura" e pasteurizado colhidas em vários pontos do fluxograma de uma usina de beneficiamento**.

\begin{tabular}{|c|c|c|c|c|c|}
\hline \multirow[b]{2}{*}{ Amostras } & \multirow{2}{*}{$\begin{array}{l}\text { Leite cru } \\
\text { Saida do } \\
\text { envase }\end{array}$} & \multicolumn{4}{|c|}{ Leite pasteurizado (pontos do fluxograma) } \\
\hline & & $\begin{array}{l}\text { Tanque de } \\
\text { estocagern }\end{array}$ & $\begin{array}{l}\text { Saida do } \\
\text { pasteurizador }\end{array}$ & $\begin{array}{l}\text { Tanque de } \\
\text { estocagem }\end{array}$ & $\begin{array}{l}\text { Tanque de } \\
\text { equilibrio }\end{array}$ \\
\hline 01 & $27.000^{\circ}$ & 100 & 200 & 100 & $700^{\circ}$ \\
\hline 02 & 6.500 & 400 & 430 & 315 & 240 \\
\hline 03 & 3.850 & 100 & $3.175^{\star}$ & $3.450^{*}$ & $2.275^{*}$ \\
\hline 04 & $10.980^{*}$ & 200 & $625^{*}$ & $600^{*}$ & 400 \\
\hline 05 & 8.450 & 400 & $4.500^{*}$ & $6.250^{x}$ & $6.500^{*}$ \\
\hline 06 & $20.250^{*}$ & 300 & $1.400^{\circ}$ & $1.150^{*}$ & $2.150^{\circ}$ \\
\hline 07 & $29.750^{\circ}$ & 100 & 300 & 450 & $1.750^{*}$ \\
\hline 08 & $183.500^{*}$ & 475 & $1.000^{\circ}$ & $900^{\star}$ & $775^{\wedge}$ \\
\hline 09 & $25.500^{*}$ & 100 & 500 & 300 & 300 \\
\hline 10 & $25.000^{\wedge}$ & 50 & 50 & 260 & 260 \\
\hline 11 & 5.275 & 5 & 40 & 95 & 70 \\
\hline 12 & 4.390 & 20 & 95 & 50 & 120 \\
\hline 13 & $13.775^{\star}$ & 100 & 200 & 300 & $800^{\circ}$ \\
\hline 14 & $13.175^{\star}$ & 50 & 50 & 200 & 100 \\
\hline 15 & $55.200^{\star}$ & 50 & 250 & 250 & 100 \\
\hline 16 & $28.675^{\circ}$ & 50 & 50 & 50 & 150 \\
\hline 17 & $20.000^{-}$ & 50 & 150 & 200 & 250 \\
\hline 18 & $33.850^{\circ}$ & 50 & $600^{\circ}$ & $600^{*}$ & 300 \\
\hline 19 & $38.925^{\star}$ & 500 & 5 & 100 & $2.050^{\circ}$ \\
\hline 20 & $13.675^{*}$ & 5 & 50 & 50 & 50 \\
\hline 21 & $15.650^{\circ}$ & 150 & 100 & 50 & 50 \\
\hline 22 & $40.800^{\circ}$ & 100 & 300 & 100 & 50 \\
\hline 23 & 9.650 & 200 & 100 & 100 & 150 \\
\hline 24 & $15.750^{\circ}$ & 500 & 500 & 100 & 150 \\
\hline × Aritmética & 27.065 & 169 & 611 & 632 & 814 \\
\hline c Geométrica & 17.803 & 95 & 218 & 242 & 316 \\
\hline
\end{tabular}

(C) Amostras fora dos padröes legais

(") Resultados em ufciml da amostra

Tabela 2. Amostras de leite pasteurizado do tipo A, fora dos padrões do ministério da agricultura, colhidas em alguns pontos do fluxograma, segundo as pesquisas de Staphylococcus aureus, coliformes totais e de coliformes fecais, 1996/97.

\begin{tabular}{|c|c|c|c|c|c|c|c|c|}
\hline \multirow[b]{3}{*}{ Microg/s. } & \multicolumn{8}{|c|}{ Amostras fora dos padróes do Ministério da Agricultura } \\
\hline & \multicolumn{2}{|c|}{$\begin{array}{c}\text { Saida do } \\
\text { pasteurizador }\end{array}$} & \multicolumn{2}{|c|}{$\begin{array}{l}\text { Tanque de } \\
\text { estocagem }\end{array}$} & \multicolumn{2}{|c|}{$\begin{array}{l}\text { Tanque de } \\
\text { equilibrio }\end{array}$} & \multicolumn{2}{|c|}{$\begin{array}{c}\text { Saída do } \\
\text { envase }\end{array}$} \\
\hline & $\pi^{\underline{2}}$ & $\%$ & $\mathrm{n}^{\mathrm{O}}$ & $\%$ & $n^{\circ}$ & $\%$ & $n^{2}$ & $\%$ \\
\hline Microrg/s. mesófilos & - & - & 6 & 25,0 & 6 & 25,0 & 8 & 33,3 \\
\hline Coliformes totais & - & - & 6 & 25,0 & 8 & 33,3 & 11 & 45,8 \\
\hline Coliformes fecais & - & - & 4 & 16,7 & 5 & 20,8 & 4 & 16,7 \\
\hline S. aureus & - & - & - & - & - & - & - & - \\
\hline Total & - & - & 6 & 25,0 & 8 & 33,3 & 11 & 45,8 \\
\hline
\end{tabular}


NADER FILHO, A., AMARAL, L.A., SCHOCKEN, D.B.L., DIMENSTEIN, A.R. Microbiological characteristics of type A "in natura" and pasteurized milk in different points of the processing fluxogram. Semina: Ci. Agr., Londrina, v.19, n.1, p.21-25, mar. 1998.

ABSTRACT: One hundred twenty samples of raw and pasteurized milk collected from different points of a processing fluxogram in a type A mini processing milk plant, were submitted to the countings of mesophylic microorganisms and to the survey of total coliformes, fecal coliforms and Staphylococcus aureus. In spite of all analized samples showing to be negative in relation to the survey of $S$. aureus, the obtained results showed that $18(75,0 \%)$ milk samples collected from the raw milk tank, as well as $6(25,0 \%), 8(33,3 \%)$ and $11(45,8 \%)$ pasteurized milk samples collected from the storage tank, balance tank and outflow of the botteeling machine, respectively, presented to be out of the legal microbiological standards.

KEY WORDS: Milk, type A milk, milk mini-processing plant.

\section{REFERÊNCIAS BIBLIOGRÁFICAS}

AMERICAN PUBLIC HEALTH ASSOCIATION (APHA). Committee on microbiological methods for foods. Compendium of methods for microbroiogical examination. Waschington, 1976.

BORGES, M.S. OLIVEIRA, J.S., MELO, A.M. Comparison of the quality of two types at two sources in the Belo Horizonte. Brazil market, J. Food Protec., v.41, n.9, p.739-742, 1978.

CARTER, G.R., COLE JUNIOR, J.R. Diagnóstic procedures in Veterinary Bacteriology and Micology, 5. ed. New York: Academic Press, 1990.

MAC FADIM, J.F. Bjochernical tests for identification of medical bacteria. Baltimore : Williams \& Wilkins, 1976.

MINISTÉRIO DA AGRICULTURA.Métodos analíticos oficiais para controle de produtos de origem animal e seus ingredientes. Brasilia : Métodos Microbiológicos, 1981.

NADER FILHO, A. Mastite estafijocbcica e caracteristicas microbiológicas do leite tipo B "in natura" o pasteurizado. Isolamento de cepas de Staphylococcus aurous, produçấo de enterotoxina e determinação da origem provável, fumana ou bovina. Jaboticabal: Faculdade de Ciências Agrárias $\odot$ Veterinárias / UNESP, 1987. (Tese de Livro-Docéncia).

NADER FILHO, A., ROSSI JÚNIOR, O.D., SCHOCKEN-ITURRINO, R.P. Avaliação das caracteristicas microbiológicas do leite tipo $\mathrm{C}$ e das embalágens plásticas utilizadas no envase, em uma usina de beneficiamento do Estado de Sto Paulo. Rev Microbiologia, Stio Paulo, v.20, n.3, p. 261-266, 1989.

NADERFILHO, A., SCHOCKEN-ITURRINO, R.P., ROSSI JÚNIOR, O.D. Avaliaçäo das características microbiológicas do leite tipo B em diferentes pontos do fluxograma de beneficiamento. Arq. Bras, Med, Vet. Zoot., Belo Horizonte, v.41, n.1, p. 7-16, 1989 .
NADER FILHO, A., AMARAL, L.A., ROSSI JÚNIOR, O.D., LUIZ, A.F Caracteristicas microbiológicas do leite pasteurizado dos tipo A, B e C, comercializados na cidade de Ribeiräo Preto, Estado de Sào Paulo. Ars Vet., Jaboticabal, v.6, n.2, p.166-172, 1990.

NASCIMENTO, D. Contribuichäo ao conhecimento das condiçōes bacteriológicas de amostras de leite tipo $C$, antos $o$ após a pasteurizacăo, vendido na cidade de Joăo Pessoa/PB. Săo Paulo : Faculdade de Ciências Farmacêuticas / USP, 1982 (Tese de Doutoramento).

OLIVEIRA, J.S., BORGES, S.F. Qualidade do leite pasteurizado. Higiene Alimentar, São Paulo, v.2, n.3, p.113-116, 1983.

ROSSI JUNIOR, O.D., NADER FILHO, A., FALEIROS, R.R., LOPES, J.L., SCHOCKENITURRINO, R,P. Análise das condiçōes físicoquímicas e bacteriológicas do leite oferecido ao comércio em JaboticabalSP. Rev. Inst. Lact. Cándido Tostes, Juiz de Fora, v.220, n.37, p.15-19, 1982.

SILVEIRA, N.V. ., SAKUMA, H., DUARTE. M., RODAS, M.A.B., SARUWATARIN J.H., CHICOUREL, E.L. Avaliaçăo das condiçoses físico-quimicas e microbiológicas do leite pasteurizado consumido na cidade de São Paulo. Rov lnst Lact. Cañndido Tostes, Juiz de Fora, v.260, n.43, p. 40-45. 1988.

VEISSEYAE, R. Lactologia tocnica. Zaragoza (España) : Acribia, 1972 . 